\title{
CORRECTION
}

\section{Estimated effects of adding universal public coverage of an essential medicines list to existing public drug plans in Canada}

CMAJ has been made aware of an error that occurred in the Feb. 27, 2017, issue. ${ }^{1}$

The statement about the incremental government cost per year if universal public coverage of an essential medicines list were added to existing public drug plans in Canada should have indicated an $11 \%$ increase in public expenditure, not an $11 \%$ reduction. The statement appears in the abstract (p. E295) and in the main Results and Interpretation sections (p. E300).

This has been corrected at www.cmaj.ca.

Cite as: CMAJ 2017 April 3;189:E511. doi: 10.1503/cmaj.170248

\section{Reference}

1. Morgan SG, Li W, Yau B, et al. Estimated effects of adding universal public coverage of an essential medicines list to existing public drug plans in Canada. CMAJ 2017;189:E295-302. 